\title{
Apogeu e colapso dos grandes cacicados no sul da Argentina: estratégias de resistência e iminência de combate (1861-1872)
}

Gabriel Passetti*

\section{RESUMO}

As relaçôes sociais, políticas e econômicas entre indígenas e criollos no sul da Argentina foram marcadas, na segunda metade do século XIX, por aproximaçóes e distanciamentos, acomodaçóes e enfrentamentos, resistências e combates. Entre 1861 e 1872, deu-se o apogeu do poder dos grandes cacicados nos pampas e na Patagônia. Senhores das terras, controladores de parte considerável do comércio e defensores de suas soberanias, sabiam quem eram seus interlocutores e estavam bem informados sobre seus dilemas, debates, interesses e estratégias. Durante e após a Guerra do Paraguai, alteraram suas formas de organização social e política para estabelecer novos patamares de resistência ao Estado: uniram forças e atacaram antes de serem atacados. Este artigo discute os dilemas daquela época e os interesses indígenas no apogeu de seu poder.

Palavras-chave: Argentina; resistências nativas; negociação e conflito.

\section{ABSTRACT}

In the second half of the nineteenth century, the social, politic and economic relationships between indigenous peoples and creoles in the south of Argentina were characterized by periods of closeness and estrangement, peace and conflict, resistance and combat. The zenith of Chiefdom rule in the Pampas and Patagonia took place between 1861 and 1872. Owners of the land, they controlled much of the commerce of the area and defended their sovereignties. They knew who were their representatives and were well informed on their dilemmas, debates, interests and strategies. During and after the Paraguayan War, they changed their social and political organization in order to establish new levels of resistance against the State: they joined forces and attacked before they were attacked. This paper discusses the dilemmas of that time and the interests of the native peoples of Argentina at the height of their power.

Keywords: Argentina; native resistance; negotiation and conflict.

DOI: http://dx.doi.org/10.1590/2237-101X01903703

Artigo recebido em 28 de abril de 2016 e aprovado para a publicação em 29 de setembro de 2017.

* Professor da Universidade Federal Fluminense. E-mail: gabrielpassetti@id.uff.br. Bolsista CNPq PQ-2.

Este artigo apresenta parte das conclusóes da tese $O$ mundo interligado: poder, guerra e território nas lutas na Argentina e na Nova Zelândia (1826-1885), defendida no Programa de Pós-graduação em História Social da USP, sob orientação da Profa. Dra. Maria Ligia Coelho Prado, com financiamento da Fapesp. 


\section{RESUMEN}

Las relaciones sociales, políticas y económicas entre indígenas y criollos en el sur de Argentina fueron marcadas, durante la segunda mitad del siglo XIX, por aproximaciones y distanciamientos, acomodaciones y enfrentamientos, resistencias y combates. Entre 1861 y 1872, se dio un crecimiento en el poder de los grandes caciques en las Pampas y en la Patagonia. Señores de las tierras, controladores de parte considerable del comercio y defensores de sus soberanías, sabían quiénes eran sus interlocutores, y estaban bien informados sobre sus dilemas, debates, intereses y estrategias. Durante y después de la Guerra del Paraguay, alteraron sus formas de organización social y política para establecer nuevos niveles de resistencia ante el Estado: unieron fuerzas y atacaron antes de ser atacados. Este artículo discute los dilemas de aquella época y los intereses indígenas en el apogeo de su poder.

Palabras clave: Argentina; resistencias nativas; negociación y conflicto.

As relaçóes sociais, políticas e econômicas entre indígenas e criollos no sul da Argentina foram marcadas, na segunda metade do século XIX, por aproximaçóes e distanciamentos, acomodaçóes e enfrentamentos, resistências e combates. O ano de 1861 marca uma importante alteração no padrão anteriormente estabelecido, pois a vitória das tropas de Buenos Aires sobre a Confederação levou, no ano seguinte, à unificação do país.

A importância desse fato, vinculado à história política institucional e às disputas entre os grupos criollos, fica ainda maior quando se considera que os indígenas eram partícipes ativos — porém não formais — da política, e que os novos donos do poder eram seus ferrenhos

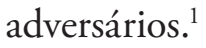

Este artigo analisa as relaçóes entre os representantes do Estado argentino e lideranças indígenas dos Pampas e da Patagônia por meio de correspondências trocadas no período e guardadas atualmente no Servicio Historico del Ejército, em Buenos Aires, em poucas fontes publicadas em coletâneas. Todas as traduçóes da documentação, tanto manuscrita quanto publicada, são de nossa autoria.

Trabalhamos com a hipótese central de que as lideranças indígenas do período eram partícipes ativas da política nacional - mesmo que de forma informal — e da economia regional, no que eram reconhecidas a contragosto pelas autoridades criollas. Dessa tensão, surgiram intensas negociaçóes e conflitos em diferentes escalas, como expresso na correspondência analisada.

$\mathrm{O}$ artigo apresenta inicialmente aspectos centrais das relações entre indígenas e criollos como estabelecidas até o marco cronológico inicial. Para tal, apoia-se nas pesquisas de histo-

\footnotetext{
${ }^{1}$ PASSETTI, Gabriel. Indigenas e criollos: política, guerra e traição nas lutas no sul da Argentina (1825-1885). São Paulo: Alameda, 2012.
} 
riadores e antropólogos argentinos, apresentados de forma sucinta em suas principais questôes e debates. Na sequência, é introduzida a nova configuração de forças estabelecida após 1861 e as profundas alteraçóes proporcionadas pela eclosão da Guerra do Paraguai. Por fim, são explicitadas as radicalizaçôes dos discursos políticos de criollos e indígenas e suas respectivas opçóes pelo enfrentamento armado na disputa por territórios, soberanias e poderes.

\section{Indígenas e criollos no sul da Argentina antes de 1861}

Nas periferias do império colonial espanhol, o território atualmente sob o Estado argentino era foco de pouco interesse e investimentos da metrópole, em comparação com outras áreas. No início do século XIX, toda a regiáo ao sul do arco fronteiriço que ia de Buenos Aires a Mendoza, passando por Córdoba e San Luís, permanecia sob controle direto de diferentes grupos indígenas. Durante as décadas seguintes, aumentaram as populaçôes nativa e criolla, suas interações e seus conflitos. ${ }^{2}$

\section{Figura 1: Principais cacicados indígenas e áreas citadas ${ }^{3}$}

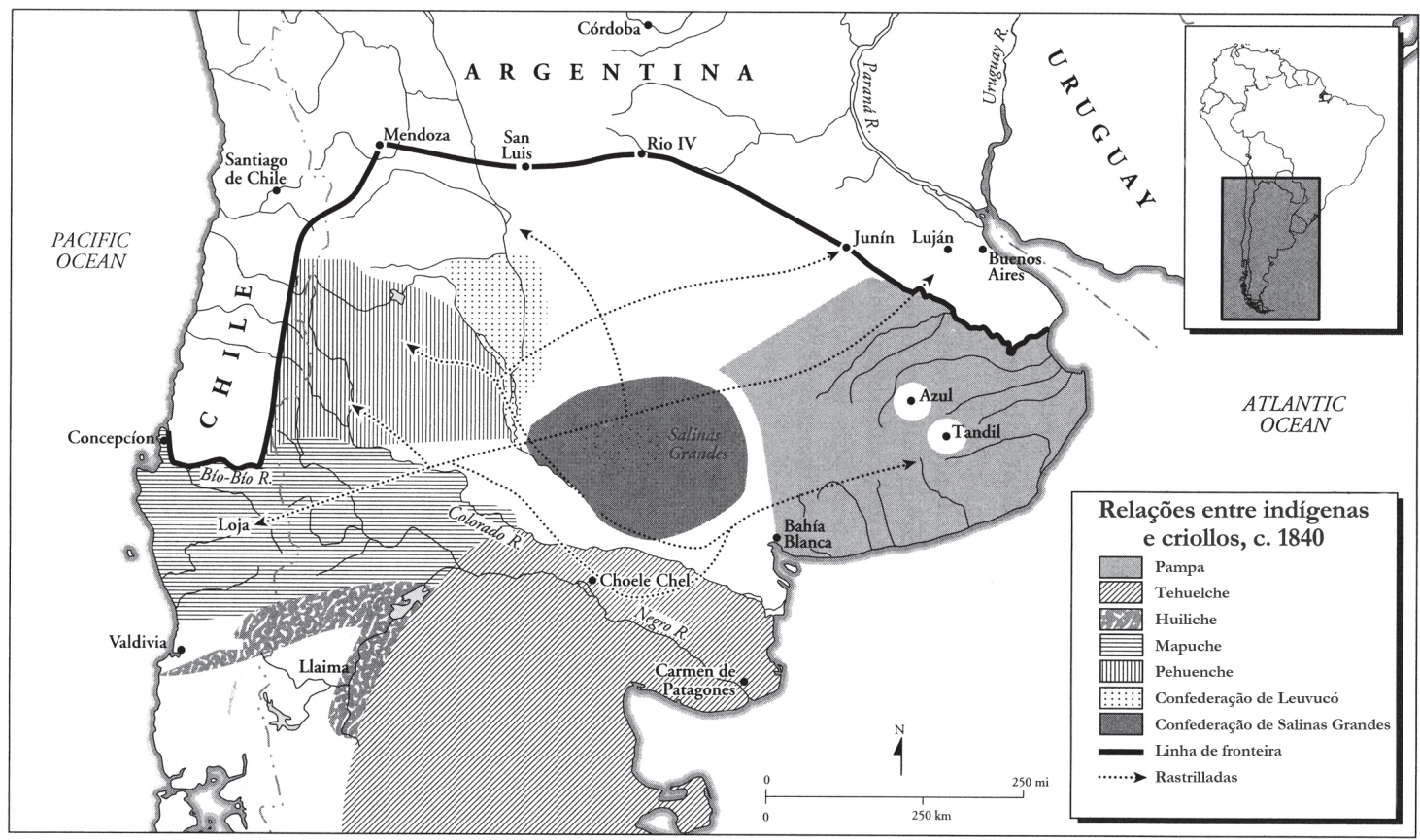

\footnotetext{
${ }^{2}$ REICHEL, Heloisa Jochims. A participação dos indígenas na construção do Estado argentino (1810-1852). Projeto História, São Paulo, v. 31, 2005.

${ }^{3}$ PASSETTI, Gabriel. Indigenas e criollos: política, guerra e traição nas lutas no sul da Argentina (1825-1885), op. cit., p. 71.
} 
Os grupos indígenas dessa região patagônico-pampeana, no século XIX, apresentavam distintos graus de mestiçagem entre si e intensos e múltiplos contatos entre os dois lados da fronteira interestatal, entre os Pampa, Tehuelche, Huiliche, Pehuenche e Mapuche. Algumas características tidas como originárias deste último grupo, como a liderança política centralizada e patrilinear e a centralidade da guerra, se disseminaram pela região. ${ }^{4}$

Eles viviam de agricultura, pecuária e caça, praticavam artesanato e estabeleceram, ao longo dos séculos, rotas através dos pampas, interligando lagoas e salinas à costa e, posteriormente, às cidades criollas. Estas eram as rastrilladas, as vias de transporte em região plana com poucas referências geográficas. ${ }^{5}$ Os principais pontos de intersecção entre essas vias, por onde transitavam pessoas, produtos e ideias, eram alvo de disputas entre famílias indígenas, bem como alvo de constantes ataques de militares espanhóis e depois argentinos. Lá estavam estabelecidas grandes feiras e também se sedimentaram poderosos cacicados — ou confederações — , sendo os mais destacados os de Salinas Grandes e Leuvucó. ${ }^{6}$

A centralização política indígena em torno da figura dos caciques foi resultado das interações entre as tradiçóes políticas e estratégias decisórias tradicionais dos Mapuche, com as pressóes por responsabilizaçóes e a urgência por decisóes rápidas, desenvolvidas a partir da convivência e do conflito com os criollos.

A vida política, social e econômica dos grupos indígenas dessa região não estava, no entanto, pautada por intensa centralização nas mãos desses caciques. Além de responderem às negociaçóes e pressóes dos criollos e de outros grupos familiares, eles também precisavam reunir capacidades de oratória, prezar pela reciprocidade e redistribuição entre seu grupo e serem reconhecidos como hábeis comandantes militares. Os cem anos entre a metade do século XVIII e o seguinte levaram a essa centralização, inclusive por conta das necessidades cotidianas da vida e das relaçôes com os criollos.

Os indígenas do sul da Argentina e do Chile, isto é, da grande área Mapuche, viviam uma relação bastante intensa com os criollos, trabalhando esporadicamente na agricultura e na pecuária, realizando cada vez mais comércio e também disputando os mercados de gado. Bovinos, equinos e ovinos criados nos pampas eram muitas vezes vendidos para o Chile, a Bolívia e o Peru e essa era uma das atividades econômicas mais ativas e rentáveis do período. E os caciques não se furtaram de participar dessas redes.

Além de criar os próprios animais, eles disputaram com os criollos o gado selvagem - chamado cimarrón - mas também não deixavam de invadir as áreas pecuaristas para realizar o roubo de gado. Às invasões indígena às terras criollas denominou-se malón e a seus

\footnotetext{
${ }^{4}$ BECHIS, Martha. Fuerzas indígenas en la política criolla del siglo XIX. In: GOLDMAN, Noemí; SALVATORE, Ricardo (Comp.). Caudillismos rioplatenses: nuevas miradas a un viejo problema. 2. ed. Buenos Aires: Eudeba, 2005.

${ }^{5}$ MANDRINI, Raúl José; ORTELLI, Sara. Volver al país de los araucanos. Buenos Aires: Sudamericana, 1992. ${ }^{6}$ DE JONG, Ingrid; ESCOBAR OHMSTEDE, Antonio. Las poblaciones indigenas en la construcción y conformación de las naciones y los estados en la América Latina decimonónica. México: CIESAS/El Colegio de Mexico, 2014.
} 
integrantes, maloneros. Essa atividade era de destacada importância, pois fornecia alimento, produtos para comercializar e garantia a força e a importância dos caciques e dos demais guerreiros do grupo. Entre os criollos, a imagem das invasóes às estancias, vilas e cidades se difundiu e se tornou simbólica das relaçôes pampeanas e do chamado "deserto".

A participação indígena nos mercados pecuaristas internos da Argentina, mas também nos outros regionais, a amplitude de sua rede de contatos e transporte e seu controle sobre importantes passagens pelos Andes proporcionaram muita força aos caciques. De tradição guerreira Mapuche, eles resistiram intensamente à perda do controle sobre seus territórios e lutaram para garantir suas soberanias. ${ }^{8}$ Alfabetizados, leitores dos jornais argentinos e chilenos, informados por suas redes de contatos no comércio, estavam familiarizados com as lideranças políticas criollas e suas lutas pelo poder. Conheciam os projetos políticos em disputa e procuraram se associar aos grupos que lhes pareceram mais interessantes e próximos.

Essa situação não agradou a seus concorrentes no comércio, aos produtores que tinham suas estancias assaltadas, a militares e políticos que se viam confrontados por soberanias autônomas e poderes vindos de populaçóes entendidas como inferiores. ${ }^{9}$ A conjunção desses fatores levou, assim como as pressóes locais, regionais e internacionais, a uma crescente tensão nas chamadas zonas de fronteira, a uma violência crescente, a tentativas incessantes do Estado e das elites para legislar sobre territórios, ocupar as terras. ${ }^{10}$

Os caciques começaram a participar mais ativamente das negociaçóes políticas e a serem considerados importantes pelos criollos durante o governo de Juan Manuel de Rosas. O poderoso governador de Buenos Aires buscou selar alianças com determinados cacicados — em especial o de Salinas Grandes — para garantir a tranquilidade e a produção pecuária. Seu objetivo final era garantir a tranquilidade na chamada campaña para garantir apoios e sua legitimidade.

A derrubada do regime de Rosas, em 1852, levou a Argentina a um período de nove anos de intensa disputa política, culminando com o cisma político entre a Província de Buenos Aires e a Confederação. Naqueles anos, as relaçôes entre indígenas e criollos se intensificaram ainda mais, com a gradativa aproximação de praticamente todos os grandes cacicados ao governo confederado, em especial à figura pessoal de seu líder, Justo José de Urquiza. O ápice dessa aliança, selada com relaçóes de compadrio, se deu nas açóes orquestradas e conjuntas entre indígenas e confederados, em 1859, na vitória sobre as tropas de Buenos Aires, na chamada Batalha de Cepeda. ${ }^{11}$

\footnotetext{
${ }^{7}$ FREITAS NETO, José Alves. A formação da nação e o vazio na narrativa argentina: ficção e civilização no século XIX. Esboços (UFSC), n. 20, 2008.

${ }^{8}$ GARAVAGLIA, Juan; GAUTREAUX, Pierre. Mensurar la tierra, controlar el territorio: America Latina, siglos XVIII-XIX. Rosario: Prohistoria ediciones, 2011.

9 OLIVEIRA, Juliana Jardim de. De muitos, um: Estado, território e narrativas nacionais nos EUA e na Argentina no século XIX. Rio de Janeiro: Multifoco, 2014.

${ }^{10}$ SECRETO, María Veronica. Fronteiras em movimento: história comparada - Argentina e Brasil no século XIX. Niterói: Eduff, 2012.

${ }^{11}$ PASSETTI, Gabriel. Confederaçôes indígenas em luta por participação política, comercial e territorial: Argentina, 1852-1859. História (São Paulo), v. 28, n. 2, 2009.
} 


\section{A construção do Estado Nacional e o combate às barbáries}

Em Facundo, publicado como livro em 1845, Domingo Faustino Sarmiento apresentou sua leitura do par opositor que veio a se tornar central para o discurso e o projeto político das elites unitárias. Para ele, havia uma distinção: "o campo, lugar da barbárie, território livre dos federalistas, e as cidades, lugar da civilização, protótipo da cultura, do progresso, da riqueza. As oposiçóes eram a uma vez políticas — federalistas contra unitários - e culturais." ${ }^{12}$

Esse esquema interpretativo não foi exclusivo da Argentina e esteve associado a um movimento típico da segunda metade do século XIX, quando em muitos países, tratou-se de "estreitar o sentimento de identidade daquelas comunidades, não só por meio da associação contratual e voluntária (...), mas também pela expansão de outras dimensóes que se converteram, muitas vezes, no fator de legitimação política desses Estados”. 13 Essas outras dimensôes, culturais e sociais, estiveram marcadas pela construção de inimigos internos, pela noção de barbárie e pela delimitação de espaços de vazio civilizacional a serem ocupados, fossem "desertos" ou "sertôes".

Essa construção espacial foi especialmente importante nos Estados de grandes dimensóes territoriais, como a Argentina, o Brasil e os Estados Unidos, para o caso do continente americano, entre outros. Nesses locais,

o deserto não apenas proporciona à nação o suporte territorial para o traçado de seus limites geográficos, também serve para apresentar um vazio, uma carência organizada coletivamente por um grupo, a ser reparada pela constituiçáo do Estado. Ao corpo repleto de terras virgens, unidades primitivas e selvagens de produção — realidade primeira da natureza e do homem — falta algo: um Estado. ${ }^{14}$

Diante do que entendiam como um imenso desafio estatal, nacional e civilizacional, os governos que sucederam à queda de Rosas associaram a elaboração de nova legislação com açôes militares para vencer suas barbáries. Entre elas, encontravam-se indígenas e caudilhos.

O novo grupo detentor do poder tinha como especial foco aqueles caciques outrora associados formalmente à Confederação Argentina:

A intensa correspondência trocada entre as tolderias e os militares de Urquiza foi uma marca das relaçôes políticas entre indígenas e criollos no período (...). Calfucurá, apesar de oficialmente

\footnotetext{
${ }^{12}$ PRADO, Maria Ligia Coelho. Para ler o Facundo de Sarmiento. In: SARMIENTO, Domingo Faustino. Facundo: civilização e barbárie. Petrópolis, RJ: Vozes, 1997, p. 26.

${ }^{13}$ SÁ, Maria Elisa Noronha de. Civilização e barbárie: a construção da ideia de nação — Brasil e Argentina. Rio de Janeiro: Garamond, 2012, p. 251.

${ }^{14}$ RODRÍGUEZ, Fermín A. Un desierto para la nación: la escritura del vacío. Buenos Aires: Eterna Cadencia, 2010, p. 397.
} 
aliado a Urquiza, ainda mantinha determinados contatos com os portenhos, recebendo gado e presentes em troca de uma suposta neutralidade. ${ }^{15}$

A associação entre os caciques e grupos políticos do Interior refratários ao projeto centralizador comandado pelos liberais manteve-se após a vitória das tropas de Mitre, em 1861. Os Ranquel do cacicado de Leuvucó se aproximaram de dois dos mais destacados caudilhos, Juan Saá, de San Luis; e Chacho Peñaloza, de La Rioja. Essa nova aliança, no entanto, jamais teve a força e a representatividade daquela anteriormente assinada com Urquiza.

$\mathrm{O}$ ápice da força indígena junto às esferas formais do poder político na Argentina havia sido ultrapassado, quando da derrota da aliança entre a Confederação e os grandes cacicados. A partir de 1862, manteve-se a força militar e econômica e a pressão política, mas o caminho se tornou mais sinuoso e as negociaçóes mais duras: cresceu a violência de ambos os lados.

O governo central, no entanto, sabia que não seria capaz de vencer todos os seus inimigos de uma vez. Enquanto combatia os caudilhos e os Ranquel no Interior, buscou a aproximação pragmática com o cacicado de Salinas Grandes, comandado por Juan Calfucurá. O objetivo, naquele momento, era emergencial: conter os malones que vinham sendo direcionados aos pampas de Buenos Aires, há uma década, para garantir o apoio dos pecuaristas daquela região e a própria legitimidade política nos âmbitos regional e provincial.

As negociações com Calfucurá envolveram o investimento, por parte do governo, em responsabilizar o cacique por malones, no que não foi bem-sucedido. Ao poderoso cacique interessava, naquele momento, avaliar o andamento dos embates entre os criollos e garantir a manutenção de sua liderança e crescente proeminência nos pampas. Dessa forma, somente aceitou a paz quando conseguiu acordos que garantissem amplo fornecimento de gado e víveres - a serem distribuídos entre os seus para legitimar sua liderança e sua posição negociadora. Ele se comprometeu a informar os comandantes militares sobre a organização de ataques indígenas às estancias, mas soube jogar com esse tipo de informação.

O que se vê, de fato, foi o inverso. Calfucurá se aproveitou das relaçóes privilegiadas com os militares para fortalecer sua posição como principal liderança indígena dos pampas, aproximando-se dos Ranquel, de Leuvucó. Logo na virada de ano de 1862 para 1863, portanto poucos meses após a tomada do poder por Mitre, o governo organizou grande expedição militar para atacar o cacicado de Leuvucó. Quando as tropas lá chegaram, não encontraram os indígenas. Os militares, intrigados, souberam, pouco tempo depois, que o insucesso foi resultado justamente de informaçôes repassadas por Calfucurá.

Com essa ação, o poderoso cacique reforçou seu lugar na política indígena, atraindo para próximo de si o grupo Ranquel — em aliança que logo se mostraria vital para ambos. Por

\footnotetext{
${ }^{15}$ PASSETTI, Gabriel. Confederaçôes indígenas em luta por participação política, comercial e territorial: Argentina, 1852-1859, op. cit., p. 126.
} 
outro lado, ele precisava defender sua posiçáo diante do governo e responder às acusaçóes de ter ajudado aos caciques inimigos.

Para tal, escreveu não apenas aos comandantes militares, mas também a outro cacique, tido pelos criollos como "índio amigo", parte daqueles "grupos das 'reduçôes', com relação muito precária com a terra, (...) com obrigaçôes de trabalho (...) centradas no serviço militar e que, basicamente, mantinham um vínculo de dependência pessoal com o governador". ${ }^{16}$ Esse "amigo" dos criollos era Ancalao:

(...) Também te aviso que (...) estou cumprindo com o Senhor Presidente minha boa fé e palavra que tenho dada a ele, e não ser falso em meus tratados que eu tenho feito com ele (...). Não peço porque sei que já se está aprontando, Coliqueo, para avançar aos Ranqueles, isto é o motivo de não pedir nada porque tenho que estar alerta (...) porque os Ranqueles marcharam a malón para a vila do Rio Cuarto (..... ${ }^{17}$

$\mathrm{Na}$ correspondência depois entregue aos militares, Calfucurá reforça sua fidelidade ao tratado e ao presidente e demonstra saber sobre a organização de nova expedição, agora contando com o apoio de mais "índios amigos", no caso Coliqueo. Para o cacique das Salinas Grandes o importante, naquele momento, era fazer chegar aos criollos a manutenção de sua aliança e também sua força e rede de informaçôes. Assim, ele garantia seu lugar de proeminência nas negociaçôes com o governo. ${ }^{18}$

Apesar de ele depois voltar a escrever, dessa vez diretamente ao Ministério da Guerra e da Marinha, afirmando que o ataque aos Ranquel "era bem feito, porque eles não querem viver em paz", ${ }^{19}$ Calfucurá jamais chegou a se constituir como um aliado ou um "índio amigo" para o governo. As palavras do ministro Gelly y Obes ao presidente Mitre sobre o caso são claras e diretas: "Catriel e Calfucurá: aí está um bom par para adornar a forca!"20 Eram sob essas tensas e inassimiláveis bases que se estruturava o tratado entre o cacicado de Salinas Grandes e o governo. Não havia aproximação programática, apenas pragmatismo de ambos os lados.

A situação não era muito distinta nos Andes Patagônicos, onde havia

uma disputa pela hegemonia, gestão dos bens em circulação e rotas de acesso. Foi fundamental que Saygüeque movesse as famílias de Paillacan e Huincahual para o sul do rio Limay e se

${ }^{16}$ RATTO, Silvia. 2003. Una experiencia fronteriza exitosa: el Negocio Pacífico de Indios en la Provincia de Buenos Aires, 1829-1853. Revista de Indias, Madri, v. 227, p. 191-222, 2003.

${ }^{17}$ Calfucurá a Ancalao, 2/4/1863. Servicio Histórico del Ejército (SHE), Fondo Guerra con el índio, Buenos Aires (tradução nossa).

${ }^{18}$ DE JONG, Ingrid. Armado y desarmado de una confederación: el liderazgo de Calfucurá en el período de la organización nacional. Quinto Sol, n. 13, p. 11-45, 2009.

${ }^{19}$ HUX, Meinrado. Caciques pampa-ranqueles. Buenos Aires: El Elefante Blanco, 1999, p. 164.

${ }^{20}$ Ibidem, p. 78. 
instalasse permanentemente no Caleufú, a porta de entrada das raçóes (...) e do caminho para o passo cordilheirano de Mamuil Malal. ${ }^{21}$

O controle dessa estratégica região de contato com o Chile gerava tensóes e conflitos locais há décadas e envolvia, inclusive, Reuque Curá, irmão de Calfucurá, além de interesses e pressóes do governo chileno. O jovem Saygüeque ainda não havia se tornado o poderoso "Senhor do País das Maçãs", expressão do viajante George Musters, mas havia conseguido assegurar o poder de sua família e fazer chegar às autoridades de Buenos Aires a notícia sobre o controle da regiáo, proporcionando-lhe um tratado, assinado em maio de 1863:

Art. $1^{\circ}$ - A tribo e os índios do Cacique Seihueque [sic], e os amigos dele poderão vir comercializar no povoado de Carmen [de Patagones] (...). De igual modo, todo habitante da República Argentina que queira ir comercializar com a dita tribo e os índios, poderá fazê-lo livremente (...).

Art. 2o - Se o Governo da República Argentina determinar explorar o rio Negro ou ocupar algum ponto militar em todo o curso dele, o Cacique Seihuque lhe prestará todos os auxílios que lhe sejam possíveis (...).

Art. 3o - O Cacique Seihueque se obriga a estar sempre pronto com seus índios para proteger e apoiar a defesa de Patagones (...).

Art. $4^{\circ}$ - Fica obrigado o Cacique Seihueque a transmitir ao comandante de Patagones e a quantas autoridades lhe seja possível, toda notícia (...) acerca de intentos ou movimentos de índios inimigos.

Art. $5^{\circ}$ - (...) serão inimigos do Cacique Seihueque todos os índios que sejam inimigos do Governo (...).

Art. $6^{\circ}$ - Em caso de resolução do Governo de atacar ou fazer expediçôes contra índios inimigos, estará obrigado o Cacique Seihuque a participar da campanha com todos os seus índios (...). Art. 8o - O Cacique Seihueque gozará de seiscentos pesos mensais, devendo constar na mesma lista onde estão Chingoleo e Huincabal (...). ${ }^{22}$

Esse tratado garantiu a hegemonia de Saygüeque sobre a estratégica região até a década de 1880 — quando se tornou alvo das tropas durante as "Campanhas do Deserto". Ele demonstra a estratégia governamental para se aproximar do controlador daquele importante acesso ao Chile, visando a vigilância sobre os fluxos mercantis e populacionais, garantir a soberania argentina sobre aquela área em litígio, mas também associar o novo poderoso cacique às redes de informantes e combatentes.

\footnotetext{
${ }^{21}$ VEZUB, Julio. Valentín Saygüeque y la Governación Indígena de las Manzanas: poder y etnicidad en la Patagonia Septentrional (1860-1881). Buenos Aires: Prometeo, 2009, p. 160-161.

${ }^{22}$ Ministro de Guerra y Marina Gelly y Obes al Comisario General de Guerra, 26/01/1865. SHE.
} 
A novidade desse tratado esteve na inserção das questôes internacionais na negociação com aquele cacicado de área fronteiriça em litígio. Ao novo governo unificado argentino, as questóes centrais pareciam estar sendo encaminhadas: caudilhos resistentes eram combatidos no interior, as questôes fronteiriças com o Chile começavam a se tornar pauta e os indígenas estavam - quase todos - sob tratados. Era estrategicamente preferível, naquele momento, acertar pazes temporárias enquanto se focava sobre outras questóes, mantendo uma postura de superioridade. $\mathrm{O}$ objetivo final não declarado era o de transformar seus territórios em terras produtivas, em inserir o liberalismo na Argentina: "a esperança recaía na constituição de um grande número de farmers para possibilitar a transformação na população, (...) substituindo aos trabalhadores rurais existentes." ${ }^{23}$

Os caciques sabiam o que estava acontecendo, entendiam os projetos governamentais e, cada um de acordo com os interesses e forças de seu grupo, procurou se movimentar, se organizar e se alinhar diante da nova conjuntura política. Naquela primeira metade da década de 1860, houve poucos avanços territoriais e poucos conflitos, com relaçóes pacíficas marcadas por uma superioridade demográfica, territorial e militar dos indígenas. Até que um fato externo alterou novamente a correlaçáo de forças.

\section{A guerra no Paraguai e as estratégias indígenas na fronteira sul argentina}

"Hoje a indiarada sabe que a República Argentina está em guerra e as fronteiras em completa acefalia, por essa razão preparam invasôes." ${ }^{24}$ Essa contundente afirmação é proveniente do comandante Benito Machado, responsável pela fronteira sul. ${ }^{25}$ Por meio dela, sabemos que, menos de um mês após a declaração formal de guerra ao Paraguai, ${ }^{26}$ a notícia circulava entre os indígenas há tempo suficiente para eles reagirem e alguém ter informado ao militar.

Historiadores e antropólogos, como Raul Mandrini, ${ }^{27}$ Martha Bechis ${ }^{28}$ e Lidia Nacuzzi ${ }^{29}$ já demonstraram as profundas tramas das redes de contatos, informaçóes e a circulação

\footnotetext{
${ }^{23}$ DELRIO, Walter Mario. Memorias de expropiación: sometimiento e incorporación indígena en la Patagonia (1872-1943). Bernal: Universidad Nacional de Quilmes, 2005, p. 93-94.

${ }^{24}$ Comandante-en-jefe Interino de la Frontera Sur (Benito Machado) a Ministerio de Guerra y Marinam, 05/07/1865. SHE.

${ }^{25}$ Sobre esse personagem central na política do sul de Buenos Aires: CANCIANI, Leonardo. El coronel Don Benito Machado. Un comandante de Guardias Nacionales en la frontera sur bonaerense (1852-1880). Mundo Agrario, v. 12, n. 24, 2012.

${ }^{26}$ DORATIOTO, Francisco. Maldita guerra: nova história da Guerra do Paraguai. Sáo Paulo: Companhia das Letras, 2002. CRESPO, Horacio; PALACIO, Juan Manuel; PALACIOS, Guillermo (Coord.). La Guerra del Paraguay. Historiografías, representaciones, contextos. México: El Colegio de México, 2012.

${ }^{27}$ MANDRINI, Raúl José. Prejuicios, mitos y estereotipos: el complejo camino de construir una historia de los aborígines de las llanuras y planícies meridionales de la actual Argentina. Revista Eletrônica da ANPHLAC, n. 17, jul./dez. 2014.

${ }^{28}$ BECHIS, Martha. Fuerzas indígenas en la política criolla del siglo XIX, op. cit.

${ }^{29}$ NACUZZI, Lidia Rosa. (Comp.) Funcionarios, diplomáticos, guerreros: miradas hacia el otro en las fronteras de pampa y patagonia (siglos XVIII y XIX). Buenos Aires: Sociedad Argentina de Antropología, 2002.
} 
de pessoas, produtos e ideias entre indígenas e criollos. Sabemos também, por meio da documentação, sobre a manutenção de espiôes governamentais nas tolderias indígenas, bem como a residência fixa de representantes formais dos grandes cacicados em Buenos Aires. As notícias, os planos, os discursos não permaneciam estanques à zona da soberania criolla.

A Guerra do Paraguai pareceu ser, a importantes cacicados como os de Salinas Grandes e de Leuvucó, a oportunidade para avançar sobre a fragilizada fronteira criolla — antes de sofrerem o previsto, declarado e anunciado ataque das forças armadas unificadas. Nas palavras do coronel Manuel Baigorria, homem de boas ligaçóes com os indígenas, "os índios declararam abertamente a guerra, rompendo com os tratados de paz celebrados, pois as invasôes ocorrem constantemente."30

$\mathrm{O}$ retorno das invasóes indígenas não pode ser lido apenas como um oportunismo por parte dos caciques, visto que eles estavam garantidos por tratados bastante lucrativos. Eles quiseram atacar e o fizeram com o objetivo claro de demonstrar forças e, eventualmente, interferir para a derrubada de um governo central que lhes era hostil.

Os comandantes da fronteira sul tiveram anos difíceis durante a prolongada guerra contra o Paraguai. Os soldados foram gradativamente remanejados para o front internacional, os armamentos não foram repostos, tampouco a munição. Segundo o historiador Leonardo Canciani, naquele momento ganharam primazia "os vecinos da campanha que foram destacados para sua defesa, (...) transformados, pela força das circunstâncias, em verdadeiros 'guardiôes' da fronteira”. ${ }^{31}$

As invasóes eram cada vez mais constantes e nem sequer as autoridades civis, responsáveis pelos corpos de milícias e pela Guarda Nacional, conseguiam ajudar. A correspondência enviada pelo juiz de paz de Junin, em dezembro de 1865, não deixa dúvidas:

Dirigi-me ao Sr. Ministro com data de 12 do corrente, fazendo conhecer a necessidade de armas e muniçôes de que se carece neste ponto, para a defesa desta localidade; com tal motivo dirigi também uma carta, com data de 10 do corrente, ao Sr. Inspetor General de Milícias da Província, pedindo a provisão deste elemento tâo necessário, e ainda muito mais nas atuais circunstâncias, em que todos os dias nos vemos ameaçados pelas invasóes dos índios selvagens (..... ${ }^{32}$

Diante dessa situação, o governo voltou a focar seus esforços na busca de um acordo com Calfucurá, entendendo que assim conseguiria conter a maior parte dos malones. Depois de mais de um ano de front duplo, de uma série ininterrupta de invasôes indígenas e da chegada de alguns milhares de lanzas provenientes da Araucania, finalmente o governo Mitre ofereceu novo tratado, este mais semelhante a um armistício:

${ }^{30}$ Inspetor General de Armas de la Província de Córdoba (Manuel Baigorria) al Ministro de Gobierno (d. Mariano Echerrique), 8/11/1865, SHE.

${ }^{31}$ CANCIANI, Leonardo. La negociación del servicio de frontera en la Guardia Nacional de Campaña Buenos Aires (1865-1870). Revista TEFROS, v. 11, n. 1-2, p. 11, 2013.

${ }^{32}$ Juez de Paz de Tapalqué al Ministro de Gobierno (Pablo Cárdenas), 21/12/1865, SHE. 
Art. 1 - Ficam estabelecidas a paz e a amizade permanente entre o governo e o cacique general D. Juan Calfucurá e os caciques que obedecem às suas ordens (...).

Art. 3- - O governo permitirá a essas tribos fazer suas caçadas nos campos que ocupam para seu comércio de peles, bem entendido que essas caçadas não poderão por nenhum motivo fazer-se nos campos de propriedade pública e particular e muito menos nos campos que ocupam as tribos amigas de Catriel, Cachul (...).

Art. $7^{\circ}$ - O cacique general d. Juan Calfucurá e os demais caciques que obedecem às suas ordens cuidarão de que os índios de sua dependência não entrem para roubar estancias nem cometer crimes de outra natureza (...). ${ }^{33}$

A análise dos termos desse acordo demonstra o objetivo imediato e urgente da paz para as estancias e a fraqueza governamental nas negociaçôes, por permitir a manutenção das caçadas que facilmente poderiam se tornar malones - e por voltar a chamar Calfucurá de cacique general.

Se o cacicado de Salinas Grandes estava temporariamente sob controle mais uma vez, e sob um tratado ainda mais desgastante para o governo, o mesmo náo se aplicava para os Ranquel de Leuvucó.

Para se compreender a vinculação desses caciques aos movimentos federalistas rebeldes dos anos 1860, ${ }^{34}$ vale retomar a análise de Ariel de la Fuente sobre as relaçóes entre gauchos e caudilhos: "era preciso negociar o apoio dos gauchos dentro das tradiçóes e símbolos, portanto dos significados do federalismo (...), uma identidade política que mantinha cativa a lealdade da maioria dos gauchos." ${ }^{35}$ Ainda segundo o mesmo historiador, "estas dificuldades para mobilizar os gauchos surgiam não apenas das próprias limitações políticas dos unitários, mas da incessante politização dos gauchos. Eram federalistas e, inclusive, em 1867 também chachistas, o que definia seu modo de participar nas lutas políticas" ${ }^{36}$

Aos interesses pessoais - alimentação, vestimenta, trabalho, dinheiro — associavam-se as redes de sociabilidade e proteção. Foi constituída uma compreensão política que associou identidade étnica gaucha a federalistas, contra as elites criollas, unitárias. Situação muito semelhante ocorreu com os indígenas e o maior exemplo foi o dos Ranquel, grupo profundamente miscigenado e aberto a esses movimentos políticos do interior. Aqueles caciques eram federalistas e assim lutaram nos anos 1860 .

\footnotetext{
33 Tratado de Paz con Calfucurá, 12/10/1866, SHE.

${ }^{34} \mathrm{O}$ período da guerra abriu oportunidades políticas para levantamentos de diferentes grupos insatisfeitos com a formaçáo do Estado Nacional como vinha ocorrendo. Para análises sobre esse período: BRAGONI, Beatriz; MÍGUEZ, Eduardo. Un nuevo orden político. Provincias y Estado Nacional 1852-1880. Buenos Aires: Biblos, 2010. SÁBATO, Hilda; LETTIERI, Alberto (Comp.). La vida politica en la Argentina del siglo XIX. Armas, votos y voces. Buenos Aires: Fondo de Cultura Económica, 2003. OSZLAK, Oscar. La formación del Estado argentino. Orden, progreso y organización nacional. Buenos Aires: Emecé, 2009.

${ }^{35}$ DE LA FUENTE, Ariel. Los hijos de Facundo: caudillos y montoneras en la Provincia de La Rioja durante el proceso de formación del Estado Nacional Argentino (1853-1870). Buenos Aires: Prometeo, 2007, p. 146. ${ }^{36}$ Ibidem, p. 151.
} 
Enquanto Calfucurá negociava o referido tratado do final de 1866, malones dos Ranquel, com o apoio dos “montoneros" Vargas e Molina, varriam regióes de San Luís e Córdoba, saqueando mais de trinta haciendas e levando aproximadamente 10 mil cabeças de gado. ${ }^{37}$

Diversas vezes os militares e as autoridades civis se mostraram contrários à política de apaziguamento dos caciques. $\mathrm{O}$ discurso geral era o de que, naquele momento específico, durante a guerra contra o Paraguai, era necessário recuar e aceitar os tratados ditos vexatórios, mas que não haveria espaço para aquele tipo de situação após o término do conflito internacional.

Esses grupos de pressão apresentaram e aprovaram na Câmara dos Deputados, em 13 de agosto de 1867 — durante a guerra - a Lei no 215 , para não deixar dúvidas sobre como o Estado argentino deveria proceder após o término do conflito internacional:

Art. 1o - Se ocupará, por forças do exército da República, ao rio 'Neuquén' ou 'Nelquen', desde seu nascimento nos Andes até sua confluência, no rio Negro, no Oceano Atlântico (...).

Art. 2o - Às tribos nômades existentes no território nacional compreendido entre a atual linha de fronteira e a fixada pelo artigo 1o desta lei, será concedido tudo o que seja necessário para sua existência fixa e pacífica.

Art. 3ํ - A extensão e limite dos territórios que se outorguem em virtude do artigo anterior, serão fixados por convênios entre as tribos que se submetam voluntariamente e o Executivo da Nação. Ficará exclusivamente ao arbítrio do Governo Nacional fixar a extensão e o limite das terras outorgadas às tribos submetidas pela força (...).

Art. $4^{\circ}$ - Em caso de todas ou algumas das tribos resistirem à submissão pacífica à autoridade nacional, será organizada contra elas uma expedição geral até que sejam submetidas (...).

Art. 9ำ - Todo o conteúdo da presente lei começará a ter efeito imediatamente após a guerra que hoje sustenta a Nação contra o Paraguai, ou antes, se for possível. O relativo ao pacto de índios, deverá começar sua execução imediatamente após sancionada pelo Executivo (...). ${ }^{38}$

Essa lei foi considerada pelos caciques como uma declaração de guerra. Ela definia todo o território pampeano-patagônico sob soberania e jurisdição do governo central, eventualmente concedendo algumas terras àqueles indígenas que se rendessem pacificamente. Ela determinava a imediata ocupação militar do território logo após o término do conflito internacional.

Para a imensa maioria dos indígenas do sul da Argentina, de tradição guerreira Mapuche, era inconcebível a opção pela submissão pacífica, pela sedentarização forçada e pela perda de autonomia. Esses eram pontos centrais de sua própria existência enquanto povo, e não seriam abandonados. E os legisladores e militares sabiam disso. Assim como também sabiam que a notícia da aprovação da lei chegaria rapidamente às tolderias. Provocaram, pois já naquele momento entendiam — equivocadamente — que a Guerra do Paraguai começava a

\footnotetext{
${ }^{37}$ HUX, Meinrado. Caciques pampa-ranqueles, op. cit., p. 176.

${ }^{38}$ WALTHER, Juan Carlos. La conquista del desierto. Buenos Aires: Círculo Militar, 1964, p. 775-776.
} 
chegar ao seu fim. Precisavam de uma reação intensa e violenta dos indígenas para mobilizar a sociedade por uma grande campanha militar, com as tropas veteranas e mobilizadas, para superar pela via armada as resistências indígenas. A sorte estava lançada para os dois lados.

\section{Unificação e combate: os indígenas e a opçáo pelo enfrentamento}

O cacicado de Salinas Grandes, sob o comando de Calfucurá e seus filhos Manuel e Bernardo Namuncurá, tornou-se o centro da organização de um movimento de resistência indígena armada. Nos pampas, na Patagônia, nos Andes e na Araucania, sabia-se que os novos grupos criollos no poder náo pretendiam mais aceitar soberanias indígenas em terras reclamadas como território nacional. Em seu entendimento, restava apenas uma atitude possível — a resistência armada.

Figura 2: As linhas sucessivas de avanço da chamada fronteira, 1852-1870 39

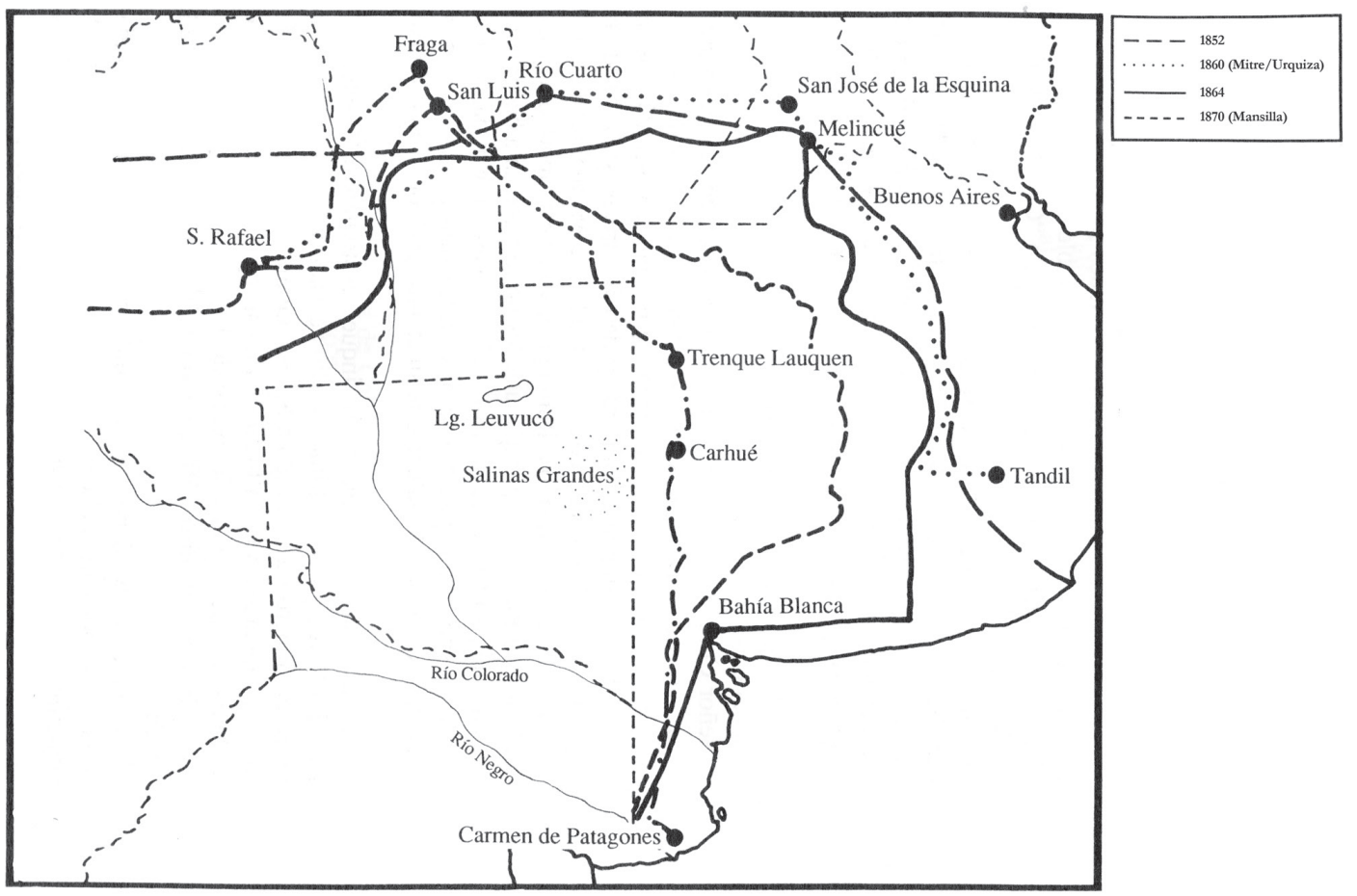

Foi articulada uma aliança entre os dois principais cacicados dos pampas, a partir da aproximaçáo com os Ranquel de Leuvucó, e acionados os contatos diplomáticos para pressionar o governo. Correspondência enviada, em setembro de 1868, a Alvaro Barros, comandante da fronteira sul, revela a tensão e a pressão daqueles tempos:

\footnotetext{
${ }^{39}$ PASSETTI, Gabriel. Indígenas e criollos: política, guerra e traição nas lutas no sul da Argentina (18251885), op. cit., p. 179.
} 
Nós dois somos amigos, (...) mas sinto muito, porque não me avisaram de sua parte, da ocupação que fizeram em Choele Choel; pois me dizem que já chegaram as forças e que vem fazer-me a guerra; mas eu também, já mandei minha comitiva para meu irmão Reuquecurá, para que mande gente e forças. Mas se se retiram de Choele Choel, não haverá nada e estaremos bem (...). Juan Calfucurá. ${ }^{40}$

Os termos utilizados foram duros e o recado foi claro: o governo deveria retirar as tropas da estratégica ilha de Choele Choel, no rio Negro. Diante da possibilidade de uma sublevação coordenada pelo cacicado de Salinas Grandes, com o reforço de milhares de araucanos, o governo recuou, mas não ignorou a movimentação.

Naquela conjuntura, os termos e as ameaças utilizadas pelos indígenas passavam a sustentar propostas de ação militar nos pampas, associando-se cada vez mais os caciques a polos alternativos de poder e de resistência à soberania "argentina" sobre aqueles territórios.

Alvaro Barros sabia que a viagem dos caciques da Araucania às Salinas Grandes não seria perdida e reconhecia a inquietação provocada pela Lei no 215 sobre os indígenas. Ele iniciou movimento para pressionar Buenos Aires por ações efetivas e ofensivas, visto que a guerra contra Solano Lopez já estava praticamente encerrada. Em correspondência ao ministério da Guerra e da Marinha, alertou para a reunião de guerreiros indígenas:

Calfucurá e os Ranquel podem por de mil e quinhentos a duas mil lanças. O cacique Limonao com uma tribo numerosa está hoje com Calfucurá, chegado há dois meses das Cordilheiras. E Reuque Curá, que dispóe de outra tribo numerosa, também está a caminho para se unir a Calfucurá. Os índios amigos situados entre este povoado [Olavarria] e Azul (1.500 lanças) até agora permanecem impassíveis, mas se não dominarmos os invasores, perder-se-á a eles (...). ${ }^{41}$

A esta correspondência, soma-se outra, com o plano de açóes para enfrentar tal reuniáo indígena:

Sendo, sem dúvida, um ataque geral o que se prepara, não há defesa possível com as forças fracionadas como estão. As pequenas divisões serão atacadas sucessivamente e, tanto por seu número quanto por sua natureza, facilmente destruídas. Reconcentrar todos em um único ponto e marchar sobre o centro de reunião do inimigo é o verdadeiro plano de defesa que dará resultado (...). Declarando a campanha em estado de sítio, em poucos dias haver-se-ão reunidos mil e quinhentos ou dois mil homens e as manadas de cavalo suficientes. Em oito dias esta força haverá ocupado as Salinas e tudo estará salvo. ${ }^{42}$

\footnotetext{
${ }^{40}$ HUX, Meinrado. Caciques pampa-ranqueles, op. cit., p. 85.

${ }^{41}$ Comandante-en-jefe de la Frontera Sur (Alvaro Barros) al Ministerio de Guerra y Marina, 06/02/1869, SHE.

${ }^{42}$ Comandante-en-jefe de la Frontera Sur (Alvaro Barros) al Inspetor General de Armas de la Nación (Emilio Conesa), 03/02/1869, SHE.
} 
Apesar das ameaças dos caciques e da análise do comandante militar, houve pouca movimentação na regiáo fronteiriça naqueles meses, intrigando aos especialistas criollos, temerosos de uma reuniáo tấo grande de guerreiros nas tolderias. Em setembro de 1869, chegou até Alvaro Barros nova correspondência, agora de Manuel Namuncurá. Ele voltava a pressionar e expressar seu poder, exigindo a saída do comandante Osorno, visto como o responsável pelo aumento da tensão na fronteira e pelas mortes de indígenas e por tropas e em encontros com criollos:

(...) nós também temos o bem pensar para o viver bem e não estarmos como inimigos, sendo filho de uma mesma terra que não podemos defender ambos mortos (...). Senhor também (...) meu pai e eu estamos muito sentidos, e outros capitáes mais, por conta do Chefe de Azul pelo que está fazendo, de assassinar a nossa gente que vai a negócio (...), se ele não marcha bem conosco teremos que nos voltar sobre o governo (...). ${ }^{43}$

Após anos costurando a aliança com o cacicado Ranquel de Leuvucó e com distintas lideranças da Araucania, bem-informados sobre o iminente fim da Guerra do Paraguai, assistindo ao gradual retorno das tropas e remilitarização da fronteira, os indígenas iniciaram sua ação ofensiva. O objetivo declarado era o de frear o avanço criollo sobre suas terras, defender sua soberania e expulsar os pecuaristas, antecipando as açôes das tropas governamentais para tentar alcançar seus objetivos estratégicos. Aquela era uma tentativa arriscada, mas era a última chance para se tentar garantir territórios e modos de vida sabidamente sob ataque.

Em junho de 1870, um primeiro grande ataque desse estilo ocorreu sobre a regiáo controlada pelo forte Arredondo, área do fortin Libertad. Haciendas foram atacadas não apenas com o objetivo tradicional de aquisição de gado, bens materiais e sequestros, mas sim para a destruição das unidades produtivas, para forçar o abandono daqueles locais pelos criollos. Com uma carga de aproximadamente 9 mil cabeças de gado, o grupo composto de supostos oitocentos maloneros foi combatido e venceu as tropas do comandante Julio Campos. ${ }^{44}$

Para a surpresa e o desespero dos comandantes militares, aquela invasáo foi pequena, quando comparada com outra, realizada em outubro do mesmo ano, com supostos 2 mil guerreiros, à cidade de Bahía Blanca, no litoral atlântico da província de Buenos Aires. Com estratégia semelhante à anterior, desta vez o resultado foi ainda maior, pois não apenas as haciendas foram destruídas, como a própria cidade, construída ao redor de uma das maiores fortalezas de entáo, a Protectora Argentina. Para militares, pecuaristas, autoridades civis e a imprensa, aquela havia sido uma grande provocação. Para os caciques, uma ação tática para tomar a dianteira em uma guerra anteriormente declarada, em 1867, com a Lei no 215.

\footnotetext{
${ }^{43}$ Manuel Namuncurá al Comandante Osorso, 19/09/1869, SHE.

${ }^{44}$ Comandante Militar del Fuerte Belgrano (Julio Campos) al Ayudante General Encargado del Despacho del Inspetor General de Armas (Rufino Victorica), 21/06/1870, SHE.
} 
A reação governamental deve ser analisada sob dois aspectos. Na média duração, acelerou-se o envio de tropas e recursos materiais para a regiáo sul, incluindo as linhas telegráficas anteriormente utilizadas no Paraguai. No tempo imediato, procurou-se Calfucurá para novo acordo no estilo de armistício, assinado já em novembro daquele ano, cujo texto se encerrava com a simbólica expressão "e isso para satisfazer ao desejo do mesmo cacique geral" ${ }^{45}$

A insatisfação dentro do governo era crescente e irradiava das vilas fronteiriças para a capital. Os relatos dos combates, dos saques, das violências e das mortes vinham sempre carregados de emoção e da nova versão do par opositor sarmientiano, não mais civilização $e$ barbárie, mas sim civilização ou barbárie. A políticos, fazendeiros, militares e parte crescente da população criolla não cabia mais, na Argentina nova e civilizada, a convivência com os indígenas, a subserviência ao poder dos caciques, a humilhação diante de soberanias alternativas e internas que atacavam as "riquezas da nação". Calfucurá não era mais um aliado incômodo, era agora apenas um líder político e militar momentaneamente muito forte, alguém ainda capaz de impor suas vontades, mas que deveria ser logo combatido.

Os comandantes militares não estavam interessados em uma negociaçáo efetiva de paz com os caciques, em chegar a um acordo mediado que incluísse aquelas populaçóes junto dos territórios na soberania argentina. Mas não eram apenas os comandantes. Também fazendeiros, comerciantes, políticos, imigrantes e tantos outros não queriam negociar com os nativos, queriam combatê-los, vencê-los, aniquilá-los. E eles sabiam que a melhor forma de conseguir isso era manter viva a instabilidade, a tensão, gerando violências, ciclos de invasóes, notícias de mortes para causar a comoção e mobilizar as poderosas tropas que retornavam do Paraguai. Era preciso mobilizar emoçóes para garantir uma pretensa uniáo nacional por verbas orçamentárias, discursos de ódio e um consenso em torno da falência do projeto de diálogo político com os caciques.

Com esse objetivo não declarado, os comandantes militares passaram a boicotar a execução dos tratados negociados com os caciques. Seguidas correspondências guardadas nos arquivos demonstram a insatisfação indígena, a indignação dos missionários e a preocupação dos órgáos reguladores do ministério de Guerra e Marinha e das contadorias civis e militares. ${ }^{46}$ Aqueles criollos, responsáveis diretos pela defesa e pelas negociaçóes com os indígenas, pretenderam instigar a violência, exacerbar a situação para torná-la inadministrável. Para tal, passaram a fornecer menos gado para os dois maiores cacicados, Salinas Grandes e Leuvucó.

Reunidos em junho de 1871, quando expedição militar tentou atacar os Ranquel, ${ }^{47}$ os líderes políticos e militares dos dois cacicados se organizaram para mais um grande ataque às zonas pecuaristas criollas, a fim de desabitar nova região. Esse tipo de planejamento era

\footnotetext{
${ }^{45}$ Tratado celebrado con Juan Calfucurá, 6/12/1870, SHE.

${ }^{46}$ Inspetor General de Armas (Emilio Mitre) al Ministerio de Guerra y Marina, 28/4/1870, SHE, por exemplo.

${ }^{47}$ PÉREZ-ZAVALA, Graciana. Tratados de paz en las pampas: los ranqueles y su devenir político (18501880). Buenos Aires: Aspha, 2014.
} 
demorado e dependia da articulação com parentes e aliados na Araucania, notícia que chegou a Buenos Aires, através dos espiôes. ${ }^{48}$

A grande questão que se colocava a comandantes militares, pecuaristas, comerciantes e habitantes das zonas fronteiriças era: onde, naquela vasta região, seria o novo ataque. Porque, diante da crescente organização e dos números cada vez maiores de guerreiros reunidos, a força dessa nova invasão seria muito grande.

Assim como ocorrera dois anos antes, sabia-se que algo grande estava sendo organizado. Os caciques das serras de Córdoba e Mendoza náo apareceram para receber o gado referente a seus tratados, ${ }^{49}$ "índios amigos" avisaram fazendeiros para recolher e trasladar seus animais, ${ }^{50}$ a tropa estava alerta, ${ }^{51}$ mas não ocorriam malones no verão de 1872.

A grande invasáo daquele ano ocorreu sobre o sul de Mendoza - área muito mais próxima da Araucania do que o litoral atlântico atacado dois anos antes. Como forma de marcar posição, Calfucurá enviou carta ao comandante militar local, informando sua chegada com milhares de indígenas para vingar injustiças cometidas contra caciques locais. Agora ele já se colocava não apenas como líder do cacicado de Salinas Grandes, mas como protetor dos indígenas contra os abusos criollos, como efetiva autoridade alternativa ao governo argentino: "por esse motivo hoje levo ao cacique Raninqueo, para que vocês não repitam isso mais uma vez com ele (...)." 52

Contando com oitenta soldados de infantaria e quarenta de cavalaria, o comandante $\mathrm{Ni}$ colas Levalle não conseguia oferecer resistência a aproximadamente 6 mil guerreiros indígenas.

Enquanto os indígenas saqueavam tudo o que encontravam, a população escrevia desesperada ao governo: "Este vecindario espera que o Superior Governo envie algumas armas e munições para poder marchar em perseguição aos índios (...). Apesar de fazer três dias que temos os índios à nossa frente, até o momento não temos nenhuma proteção." ${ }^{33}$ Aos civis e aos caciques transcorria tudo conforme o esperado, mas o resultado daquele que foi o maior malón da história da Argentina foi uma novidade.

Três mil indígenas levando mais de 50 mil cabeças de gado vacum e 10 mil equinos $^{54}$ compunham um corpo lento e previsível se deslocando pelos pampas, quando saíram no dia 9 de março de 1872. O que eles não contavam era com a disseminação instantânea da informação do ataque, por meio dos cabos telegráficos, dias antes. Como o chamado "deserto"

\footnotetext{
${ }^{48}$ Ayudante General Encargado del Despacho del Inspetor General de Armas (Rufino Victorica) al Ministerio de Guerra y Marina, 31/7/1871, SHE.

${ }^{49}$ Jefe Accidental de la Frontera Sur de Mendoza al Comandante General de las Fronteras del Interior (d. J. Arredondo), 12/6/1871, SHE.

${ }^{50}$ Pedro Gómez al Gobernador de la Província de Mendoza, 20/8/1871, SHE.

${ }^{51}$ Ayudante General Encargado del Despacho del Inspetor General de Armas (Rufino Victorica) al Ministerio de Guerra y Marina, 31/8/1871, SHE.

52 WALTHER, Juan Carlos. La conquista del desierto, op. cit., p. 451-452.

${ }^{53}$ Comandante del Fortín San Carlos (Comantande De Boer) al General Ignacio Rivas, 7/3/1872 (3), SHE.

${ }^{54}$ Sub-inspetor del Centro al Ministro de Gobierno, 8/3/1872, 6h25, SHE.
} 
não era mais desconhecido dos comandantes militares e seu rumo era notório, a estratégia adotada pelo governo foi organizar a repressáo à medida que os saques ocorriam, convocando todos os soldados à disposição, a Guarda Nacional e os "índios amigos". 55

Naquela que ficou conhecida como "a batalha de San Carlos", estavam milhares de guerreiros dos dois lados, lutando homem a homem, envoltos por uma inacreditável manada de animais desesperados pelo tiroteio. Cansados, cercados e combatidos por armas muito mais ágeis e precisas do que as que estavam acostumados a enfrentar, os indígenas sofreram uma histórica derrota. ${ }^{56}$ Grande em números e em significado, pois as baixas entre as tropas lutando pelo lado criollo foram ínfimas se comparadas aos mais de duzentos mortos entre os indígenas, e marcante porque naquele malón estava em jogo o despovoamento de uma importante regiáo pecuarista, executado pela maior reunião de caciques já ocorrida até então, contra-atacada por militares sem disposição para negociar, amparados pelas novas tecnologias bélicas.

A derrota foi enorme e marcou o início do ocaso do poder indígena no sul da Argentina. Se o auge do poder político havia passado com a derrota de Urquiza em 1861, agora chegara a decadência na correlação de forças militares. Na nova conjuntura, distintos grupos criollos se aproximaram e reorganizaram para construir novo discurso, pela aniquilaçáo física dos indígenas.

\section{Conclusão: decadência após San Carlos}

A chamada "batalha de San Carlos" marcou a alteração na curva de poder nos pampas e na Patagônia argentina. Se até aquele momento era consensual a predominância, a força e a soberania exercidas pelos caciques, a situação se alterou dramaticamente em pouco tempo.

Em dez anos de governos liberais, a Argentina se transformou profundamente. Nos primeiros anos o esforço se centrou sobre o combate às resistências criollas internas, os chamados caudilhos e suas "montoneras". A eles, estavam associados os caciques Ranquel de Leuvucó, em declarada aliança programática de enfrentamento ao governo central.

Enquanto não se conseguia eliminar as soberanias indígenas, em especial a de Salinas Grandes, optou-se por negociar a partir da compreensão da impossibilidade de enfrentar tantos adversários simultaneamente.

Naqueles anos, a liderança e proeminência de Calfucurá sobre a área pampeano-patagônica cresceu e alcançou seu ápice a partir do momento que chegaram às tolderias as notícias sobre a aprovação da Lei no 215, de ocupaçáo daqueles territórios, ainda durante a Guerra do Paraguai.

\footnotetext{
${ }^{55}$ Jefe del Batallón de Línea de San Carlos (Nicolás Levalle) al Comandante-en-Jefe de la Frontera (Nicolás Campos), 6/3/1872, 10h, SHE.

${ }^{56}$ Comandante-en-jefe de la Frontera Costa Sur (Ignacio Rivas) al Inspetor y Comandante General de Armas, 11/3/1872, SHE.
} 
Esse ponto de inflexáo marcou o próximo período de cinco anos, caracterizado pelos esforços indígenas para frear o avanço criollo e pela crescente reunião de lideranças e guerreiros em torno de um novo discurso, em diálogo com o indigenismo e com o nacionalismo, de defesa territorial e cultural. As antigas associaçóes étnicas entre caciques e federalistas foram revividas para revigorar a oposição, agora entre os indígenas, entre as esferas inconciliáveis do pensamento sarmientiano. Também no pensamento nativo, a partir em especial de 1867, não havia mais conciliação entre "nós-indígena" e o "outros-criollo".

Os guerreiros dos dois lados de uma fronteira construída, porém sempre fluida, entenderam que a guerra era a única solução - para desespero dos antigos defensores da incorporação, como os missionários. Os caciques, leitores dos jornais da capital, conhecedores da legislação e dos comandantes militares, sabiam que a organização de uma grande expedição militar para liquidar suas soberanias era apenas questão de tempo. Resolveram agir antes de serem derrotados. Guerreiros que eram, partiram para a ação ofensiva enquanto lhes restava tempo.

Aos comandantes militares, fazendeiros, comerciantes, políticos, colonos e imigrantes, a violência indígena era interessante. Sabedores de sua inferioridade demográfica, econômica e militar no âmbito local, entendiam que apenas a disseminação das notícias sobre violências, agressôes, ataques e mortes poderiam mobilizar as elites políticas e econômicas do governo central e das outras províncias para uma mobilização "nacional" contra os caciques do sul. No entendimento daqueles criollos, era preciso mais violência, para garantir o apoio ao uso da solução violenta definitiva.

A Guerra do Paraguai tensionou ainda mais essa situação. $\mathrm{O}$ conflito internacional fez os fortes e fortines da fronteira sul serem desguarnecidos, perderem homens, cavalos e armamentos, proporcionando mais força e espaço para a luta indígena. No entanto, a vitória final também levou a uma nova situação, pois proporcionou ao governo central de Buenos Aires a constituição de um exército efetivamente "nacional", com milhares de soldados mobilizados e armados com os novos inventos da guerra, fossem os rifles, os telégrafos, os navios a vapor ou os trens.

A partir do desfecho final do conflito internacional, o equilíbrio de forças na regiáo patagônico-pampeana passou a pender para o lado criollo - e os caciques sabiam disso. Eles reconheceram as provocaçóes dos comandantes militares, tentaram negociar armistícios, mas perceberam que apenas reunindo a todos - e com o apoio de parentes e aliados da Araucania - poderiam tentar resistir a aquela pressão por suas terras. Conseguiram, em 1870 e 1872, realizar enormes invasóes às zonas pecuaristas, em um esforço para demonstrar força, despovoar regiôes e tentar impor condiçôes definitivas de negociação. Foram bem-sucedidos na primeira vez, mas derrotados dois anos depois.

A nova relação de forças após a "batalha de San Carlos" expôs apenas uma prévia do que viria na sequência. Uma série considerável de caciques procurou a via dos tratados, mas, 
agora em situação de inferioridade, passaram a aceitar os deslocamentos forçados, a sedentarização, as escolas, os missionários e o serviço militar. ${ }^{57}$ Outros partiram para a resistência última e obstinada, esperançosos de uma nova reviravolta na sempre tumultuada política oficial criolla.

A nova geração de comandantes militares, entre os quais se destacavam Julio Argentino Roca e Alvaro Barros, pretendia executar o quanto antes a Lei no 215 e inserir a Argentina no que entendiam como o rol das grandes naçóes civilizadas. Para aquela linha de pensamento, não havia mais espaço algum para os indígenas e era apenas questão de tempo eliminá-los do território. ${ }^{58}$ Este foi seu esforço, entre 1872 e 1879.

\section{Referências bibliográficas}

BECHIS, Martha. Fuerzas indigenas en la politica criolla del siglo XIX. In: GOLDMAN, Noemí; SALVATORE, Ricardo (Comp.). Caudillismos rioplatenses: nuevas miradas a um viejo problema. Buenos Aires: Eudeba, 2005.

BRAGONI, Beatriz; MÍGUEZ, Eduardo. Un nuevo orden politico. Provincias y Estado Nacional 1852-1880. Buenos Aires: Biblos, 2010.

CANCIANI, Leonardo. El coronel Don Benito Machado. Un comandante de Guardias Nacionales en la frontera sur bonaerense (1852-1880). Mundo Agrario, v. 12, n. 24, 2012. . La negociación del servicio de frontera en la Guardia Nacional de Campaña Buenos Aires (1865-1870). Revista TEFROS, v. 11, n. 1-2, 2013.

CRESPO, Horacio; PALACIO, Juan Manuel; PALACIOS, Guillermo (Coord.). La Guerra del Paraguay. Historiografías, representaciones, contextos. México: El Colegio de México, 2012.

DE JONG, Ingrid. Armado y desarmado de una confederación: el liderazgo de Calfucurá en el período de la organización nacional. Quinto Sol, n. 13, p. 11-45, 2009.

DE JONG, Ingrid; ESCOBAR OHMSTEDE, Antonio. Las poblaciones indígenas en la construcción y conformación de las naciones y los estados en la América Latina decimonónica. México: CIESAS/El Colegio de Mexico, 2014.

DE LA FUENTE, Ariel. Los hijos de Facundo: caudillos y montoneras en la Provincia de La Rioja durante el proceso de formación del Estado Nacional Argentino (1853-1870). Buenos Aires: Prometeo, 2007.

\footnotetext{
${ }^{57}$ TAMAGNINI, Marcela; PÉREZ-ZAVALA, Graciana. El fondo de la tierra: destinos errantes en la frontera sur. Rio Cuarto: UNRC, 2010.

${ }^{58}$ SALOMÓN TARQUINI, Claudia. Largas noches en La Pampa. Itinerarios y resistencias de la población indígena, 1878-1976. Buenos Aires: Prometeo, 2010; LLANQUINAO, Margarita; POZO, Gabriel. Historia y conocimiento oral mapuche. Sobrevivientes de la "Campaña del Desierto" y "Ocupación de la Araucania" (1899-1926). Santiago: Catalonia, 2014.
} 
DELRIO, Walter Mario. Memorias de expropiación: sometimiento e incorporación indígena en la Patagonia (1872-1943). Bernal: Universidad Nacional de Quilmes, 2005.

DORATIOTO, Francisco. Maldita guerra: nova história da Guerra do Paraguai. São Paulo: Companhia das Letras, 2002.

FREITAS NETO, José Alves. A formação da nação e o vazio na narrativa argentina: ficção e civilização no século XIX. Esboços (UFSC), n. 20, 2008.

GARAVAGLIA, Juan; GAUTREAUX, Pierre. Mensurar la tierra, controlar el territorio: America Latina, siglos XVIII-XIX. Rosario: Prohistoria ediciones, 2011.

HUX, Meinrado. Caciques huiliches y salineros. Buenos Aires: Marymar, 1991. . Caciques pampa-ranqueles. Buenos Aires: El Elefante Blanco, 1999.

LLANQUINAO, Margarita; POZO, Gabriel. Historia y conocimiento oral mapuche. Sobrevivientes de la "Campańa del Desierto" y “Ocupación de la Araucania” (1899-1926). Santiago: Catalonia, 2014.

MANDRINI, Raúl José. Prejuicios, mitos y estereotipos: el complejo camino de construir una historia de los aborígines de las llanuras y planícies meridionales de la actual Argentina. Revista Eletrônica da ANPHLAC, n. 17, jul./dez. 2014.

MANDRINI, Raúl José; ORTELLI, Sara. Volver al país de los araucanos. Buenos Aires: Sudamericana, 1992.

MUSTERS, George Chasworth. Vida entre los patagones. Buenos Aires: El Elefante Blanco, 1997.

NACUZZI, Lidia Rosa (Comp.). Funcionarios, diplomáticos, guerreros: miradas hacia el otro en las fronteras de pampa y patagonia (siglos XVIII y XIX). Buenos Aires: Sociedad Argentina de Antropología, 2002.

OLIVEIRA, Juliana Jardim de. De muitos, um: Estado, território e narrativas nacionais nos EUA e na Argentina no século XIX. Rio de Janeiro: Multifoco, 2014.

OSZLAK, Oscar. La formación del Estado argentino. Orden, progreso y organización nacional. Buenos Aires: Emecé, 2009.

PASSETTI, Gabriel. Confederações indígenas em luta por participação política, comercial e territorial: Argentina, 1852-1859. História (São Paulo), v. 28, n. 2, 2009.

. Indígenas e criollos: política, guerra e traição nas lutas no sul da Argentina (18251885). São Paulo: Alameda, 2012.

PÉREZ-ZAVALA, Graciana. Tratados de paz en las pampas: los ranqueles y su devenir político (1850-1880). Buenos Aires: Aspha, 2014.

PRADO, Maria Ligia Coelho. Para ler o Facundo de Sarmiento. In: SARMIENTO, Domingo F. Facundo: civilização e barbárie. Petrópolis, RJ: Vozes, 1997. 
RATTO, Silvia. Una experiencia fronteriza exitosa: el Negocio Pacífico de Indios en la Provincia de Buenos Aires, 1829-1853. Revista de Indias, Madri, v. 227, p. 191-222, 2003. REICHEL, Heloisa Jochims. A participação dos indígenas na construção do Estado argentino (1810-1852). Projeto História, São Paulo, v. 31, 2005.

RODRÍGUEZ, Fermín A. Un desierto para la nación: la escritura del vacío. Buenos Aires: Eterna Cadencia, 2010.

SÁ, Maria Elisa Noronha de. Civilização e barbárie: a construção da ideia de nação - Brasil e Argentina. Rio de Janeiro: Garamond, 2012.

SÁBATO, Hilda; LETTIERI, Alberto (Comp.) La vida politica en la Argentina del siglo XIX. Armas, votos y voces. Buenos Aires: Fondo de Cultura Económica, 2003.

SALOMÓN TARQUINI, Claudia. Largas noches en La Pampa. Itinerarios y resistencias de la población indígena, 1878-1976. Buenos Aires: Prometeo, 2010.

SECRETO, María Veronica. Fronteiras em movimento: história comparada - Argentina e Brasil no século XIX. Niterói: Eduff, 2012.

TAMAGNINI, Marcela; PÉREZ-ZAVALA, Graciana. El fondo de la tierra: destinos errantes en la frontera sur. Rio Cuarto: UNRC, 2010

VEZUB, Julio. Valentín Saygüeque y la Governación Indígena de las Manzanas: poder y etnicidad en la Patagonia Septentrional (1860-1881). Buenos Aires: Prometeo, 2009.

WALTHER, Juan Carlos. La conquista del desierto. Buenos Aires: Círculo Militar, 1964.

\section{Como citar}

PASSETTI, Gabriel. Apogeu e colapso dos grandes cacicados no sul da Argentina: estratégias de resistência e iminência de combate (1861-1872). Topoi. Revista de História, Rio de Janeiro, v. 19, n. 37, p. 57-79, jan./abr. 2018. Disponível em: <www.revistatopoi.org>. 